\title{
CRESCIMENTO DEALFACE HIDROPÔNICA SOB DIFERENTES INTERVALOS DE IRRIGAÇÃO
}

\author{
Hydroponic lettuce growth under differents irrigation intervals
}

\author{
Fábio Zanella ${ }^{1}$, Ana Lúcia da Silva Lima², Francisco Ferreira da Silva Júnior ${ }^{3}$, Sivaldo Péricles Alcântara Maciel ${ }^{3}$
}

\begin{abstract}
RESUMO
O intervalo entre irrigações é um importante critério a ser observado durante o cultivo hidropônico de hortaliças. Nesse contexto, objetivou-se com este trabalho avaliar a produtividade de duas cultivares de alface (Lactuca sativa L.), Regina 2000 e Lucy Brown sob três intervalos de irrigação. O experimento foi conduzido no Centro Universitário Luterano de Ji-Paraná (CEULJI/ ULBRA), entre setembro e dezembro de 2006. Foram testados três intevalos entre irrigações: 5; 15 e 30 minutos. Cada tratamento constou de quatro repetições de cada cultivar, em delineamento inteiramente casualisado. Analisou-se o número de folhas.planta ${ }^{-1}$, a massa fresca e massa seca total de cada planta. O aumento no intervalo entre irrigações levou a uma menor produção da alface. Assim, o intervalo de 5 minutos entre irrigações promoveu o maior ganho de massa para as duas cultivares avaliadas.
\end{abstract}

Termos para indexação: Hidroponia, Lucy Brown, produção, Regina 2000.

\section{ABSTRACT}

The interval among irrigations is an important criterion taken into account during the hidroponic cultivation of vegetables. Thus, the present work aimed to evaluate the productivity of two lettuce (Lactuca sativa L.) cultivars, Regina 2000 and Lucy Brown, in three irrigations intervals. The experiment was carried out at the Centro Universitário Luterano de Ji-Paraná (CEULJ/ULBRA), from September to December 2006. Three intervals between irrigations were used: 5; 15 and 30 minutes. Each treatment had four replications of both cultivars, in a complete randomized outline. The number of leaves.plant ${ }^{-1}$, total fresh mass and total dry mass were analyzed. There was an increase of the lettuce production according to the increase of the irrigation interval. Thus, 5 minutes among irrigations promoted the greater gain of mass for both cultivars evaluated.

Index terms: Hydroponics, Lucy Brown, production, Regina 2000.

(Recebido em 22 de março de 2007 e aprovado em 27 de setembro de 2007)

\section{INTRODUÇÃO}

A alface (Lactuca sativa L.) é uma planta herbácea anual, pertencente à família Asteraceae, sendo considerada a hortaliça folhosa mais importante na alimentação do brasileiro, o que assegura a essa cultura, expressiva importância econômica (CARVALHO et al., 2005).

No estado de Rondônia, o excesso de chuvas no verão e as altas temperaturas anuais configuram-se como grandes barreiras à produção de hortaliças. A produção de alface, bem como de outras hortaliças é mais intensa nos cinturões verdes das cidades mais populosas do estado, como Porto Velho, Ji-Paraná e Cacoal. Apesar desta produção, cerca de $80 \%$ do consumo de hortaliças provém da importação de outros Estados (COSTA, 2003).

Em função de um consumo crescente e versátil de alface, exige-se qualidade e regularidade de oferta deste produto. Isso tem refletido diretamente nas áreas de produção que, para atender a esta importante demanda do mercado, comprometem-se a modernizar, sendo esta realidade transformada em importantes introduções tecnológicas, com consequiente aprimoramento técnico da mão-de-obra (SILVA et al., 1999).

Dentre várias tecnologias introduzidas no cultivo de hortaliças, o cultivo hidropônico vem-se destacando muito no Brasil, especialmente por viabilizar a disponibilidade dos produtos em períodos de entresafra e garantir uma regularidade em sua oferta (CASTELLANE \& ARAÚJO, 1994).

A alface é a planta cultivada em maior escala pelo cultivo hidropônico denominado de NFT - "Nutrient Film Technique" ou fluxo laminar de solução. Isso se deve à sua fácil adaptação ao sistema, no qual tem revelado alto

\footnotetext{
${ }^{1}$ Engenheiro Agrônomo, Doutor em Biologia Vegetal - Departamento de Agronomia e Biologia - Centro Universitário Luterano de Ji-Paraná/CEULJI Universidade Luterana do Brasil/ULBRA - Avenida Universitária, 762 A - Aurélio Bernardi - Cx. P. 271 - 78961-970 - Ji-Paraná, RO - zanellaf@yahoo.com.br ${ }^{2}$ Bióloga, Doutora em Biologia Vegetal - Departamento de Agronomia e Biologia - Centro Universitário Luterano de Ji-Paraná/CEULJI - Universidade Luterana do Brasil/ULBRA - Avenida Universitária, 762 A - Aurélio Bernardi - Cx. P. 271 - 78961-970 - Ji-Paraná, RO - limaals@yahoo.com.br ${ }^{3}$ Graduados em Engenharia Agronômica - Departamento de Agronomia e Biologia - Centro Universitário Luterano de Ji-Paraná/CEULJI - Universidade Luterana do Brasil/ULBRA - Avenida Universitária, 762 A-Aurélio Bernardi - Cx. P. 271 - 78961-970 - Ji-Paraná, RO - franciscofjunior@yahoo.com.br; spampericles@hotmail.com
} 
rendimento e reduções de ciclo em relação ao cultivo no solo (OHSE et al., 2001).

No sistema NFT, a solução nutritiva é bombeada de um reservatório, passa pelas raízes das plantas nos canais de cultivo e volta ao reservatório por gravidade (FAQUIN \& FURLANI, 1999). A circulação da solução nutritiva neste sistema pode ser continua ou intermitente (GÜL et al., 2001). No sistema intermitente, o intervalo entre as irrigações representa a freqüência com que a solução nutritiva é bombeada até as raízes das plantas.

Segundo Pillau et al. (2002), a frequiência adequada entre as irrigações, além de possibilitar o crescimento das plantas, determina um menor consumo de energia elétrica, promovendo então maior ganho econômico na produção.

Há uma estreita relação entre o tempo de repouso do sistema de irrigação, e as condições ambientais durante o cultivo, como umidade e temperatura do ar (FURLANI, 1997; MORAES, 1997).

São freqüentes os relatos na literatura sobre estudos com intervalos entre irrigações de 15 minutos ou mais, desenvolvidos principalmente no centro-sul do Brasil. Entretanto, estudos abordando intervalos menores são imprescindíveis em regiões mais quentes, como o Estado de Rondônia.

Dessa forma, conduziu-se este trabalho com o objetivo de avaliar a produtividade de duas cultivares de alface, Regina 2000 e Lucy Brown, em cultivo hidropônico NFT sob três intervalos de irrigação, no município de JiParaná/RO.

\section{MATERIAL E MÉTODOS}

O experimento foi conduzido entre setembro e dezembro de 2006, no Centro Universitário Luterano de JiParaná (CEULJI/ULBRA), situado no município de JiParaná, localizado na região central do estado de Rondônia, à $10^{\circ} 52^{\prime} 53^{\prime \prime}$ de latitude sul e 61³0'45" longitude oeste, com altitude média de $159 \mathrm{~m}$. Segundo classificação de Köppen, o clima da região é caracterizado como CWa (tropical-quente e úmido). A temperatura média anual oscila em torno de $25^{\circ} \mathrm{C}$, com precipitação pluviométrica anual de $2.250 \mathrm{~mm}$ e umidade relativa do ar média de $85 \%$.

Os ensaios foram feitos em casa-de-vegetação do tipo arco com $250 \mathrm{~m}^{2}$ de área $(10 \mathrm{~m}$ x $25 \mathrm{~m})$, pé direito de 3,75 $\mathrm{m}$ e cobertura com filme plástico de $150 \mathrm{~mm}$ de espessura. As bancadas de cultivo foram dimensionadas em $6 \mathrm{~m} \times 1 \mathrm{~m}$, altura média de 1,0 $\mathrm{m}$ do nível do solo e declividade de 2,5 $\%$. Os perfis utilizados foram de polipropileno, pintados externamente de branco, com dimensões de $50 \mathrm{~mm}$ de diâmetro e $10 \mathrm{~cm}$ entre plantas na bancada tipo berçário e
$100 \mathrm{~mm}$ de diâmetro e $25 \mathrm{~cm}$ entre plantas para a bancada de produção final. Durante o período experimental, a temperatura média foi de $29,3^{\circ} \mathrm{C}$ (Figura 1), obtida com base nas temperaturas diárias máximas e mínimas.

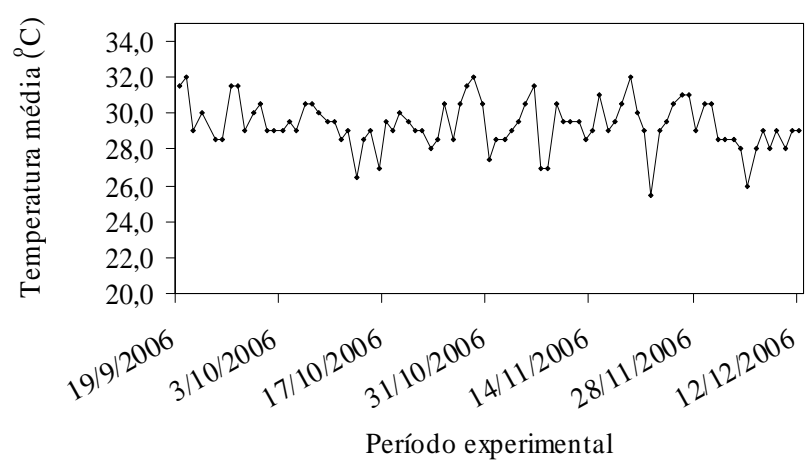

Figura 1 - Temperaturas médias durante o período experimental, obtidas com base nas temperaturas máximas e mínimas diárias, em Ji-Paraná/RO, 2006.

Foi utilizado o sistema de cultivo hidropônico NFT, utilizando-se a solução nutritiva recomendada por Castellane \& Araújo (1995), alterando-se apenas a fonte original do elemento Ferro, substituindo-se o Fe-EDTA pelo Tenso-Fe.

Utilizou-se a alface (Lactuca sativa L.) como material de estudo, cultivares Regina 2000 (grupo lisa) e Lucy Brown (grupo americana). A semeadura foi feita em espuma fenólica, com células dimensionadas em 2 $\mathrm{cm} \times 2 \mathrm{~cm} \times 2 \mathrm{~cm}$. Foram depositadas duas sementes nuas por célula. Após a emissão do primeiro par de folhas, houve um desbaste, permanecendo apenas uma muda por célula. Durante este período as mudas foram irrigadas com solução nutritiva diluída para $25 \%$ de sua concentração. Com treze dias após a semeadura (DAS), após atingirem de 4 a 5 folhas definitivas, as mudas foram transplantadas para o berçário. Após uma permanência de nove dias no berçário, sendo irrigadas em intervalos de 15/15 minutos (ligado/desligado), durante as 24 horas do dia, as plantas foram transferidas à bancada de produção final, onde permaneceram por \pm 23 dias sob os tratamentos.

Os tratamentos consistiram-se nos seguintes intervalos de irrigação:

- 5 min (15 minutos ligado e 5 minutos desligado);

- 15 min (15 minutos ligado e 15 minutos desligado);

- 30 min (15 minutos ligado e 30 minutos desligado); 
Estes intervalos foram utilizados no período das $06 \mathrm{~h} 00 \mathrm{~min}$ às $22 \mathrm{~h} 00 \mathrm{~min}$. No período noturno foram feitas três irrigações de 15 minutos, às $0 \mathrm{~h} 00 \mathrm{~min} ; 2 \mathrm{~h} 00 \mathrm{~min}$ e $4 \mathrm{~h} 00 \mathrm{~min}$. Durante a realização dos tratamentos, as plantas foram supridas com solução nutritiva diluída para $50 \%$ de sua concentração, resultando em um condutividade elétrica de aproximadamente $1,2 \mathrm{mS} . \mathrm{cm}^{-1} \mathrm{e} \mathrm{pH}$ em torno de 6,2 . O controle dos períodos de irrigação e desligamento do sistema foi feito por meio de um "timer" ligado à moto-bomba.

Cada tratamento foi constituído por 4 repetições de cada cultivar, com as plantas dispostas em delineamento experimental inteiramente casualisado, sendo cada parcela constituída por 20 plantas de cada cultivar. Ao término da imposição dos tratamentos, as seguintes variáveis foram analisadas: número de folhas; massa fresca e massa seca da parte aérea e do sistema radicular. Para a obtenção da massa seca, as folhas, caules e raízes de cada repetição foram colocados em sacos de papel e secados em estufa com ventilação forçada, $\mathrm{a} \pm 70^{\circ} \mathrm{C}$, por aproximadamente 36 horas, tempo necessária à obtenção de massa constante.

Os dados obtidos foram submetidos à análise de variância, sendo as médias comparadas pelo teste de Tukey a $5 \%$ de probabilidade.

\section{RESULTADOS E DISCUSSÃO}

O número médio de folhas é apresentado na Tabela 1. Na cultivar Regina 2000, os valores obtidos nos tratamentos 5 min e 15 min foram de 30 e 31 folhas.planta ${ }^{1}$, respectivamente, sendo significativamente superiores aos obtidos no intervalo de $30 \mathrm{~min}$ entre irrigações, que foi de 20,8 folhas.planta ${ }^{-1}$. Em pesquisa também realizada em Ji-Paraná, Carvalho et al. (2005) relatam valores entre 35 e 40 folhas.planta ${ }^{-1}$ para a Regina 2000 cultivada no solo.

A cultivar Lucy Brown também apresentou um menor número de folhas conforme se aumentou o intervalo entre as irrigações. Contudo, houve diferença significativa somente entre tratamentos $5 \mathrm{~min}$ e $30 \mathrm{~min}$, cujos resultados apresentados foram 15,3 e 10,5 folhas.planta ${ }^{-1}$. Estes valores foram muito inferiores aos obtidos por Feltrim et al. (2005), que encontraram valor médio de 29 folhas para a cultivar Lucy Brown.

O intervalo entre irrigações de 5 min proporcionou o maior acúmulo de massa fresca nas plantas das duas cultivares avaliadas (Tabela 1). Neste tratamento, foram obtidos 200,5 g.planta ${ }^{-1}$ (Regina 2000) e 192,3 g.planta ${ }^{-1}$ (Lucy Brown).

No tratamento de $15 \mathrm{~min}$ os valores foram de 178,0 e 124,4 g.planta ${ }^{-1}$, para a Regina 2000 e Lucy Brown, respectivamente. As plantas mantidas sob 30 min entre as irrigações apresentaram os menores valores médios de massa fresca acumulada, sendo de 73,3 g. planta $^{-1}$ (Regina 2000) e 67,3 g.planta ${ }^{-1}$ (Lucy Brown). Casaroli et al. (2003), em cultivos nos meses de março a abril, obtiveram 334,6 g para a cultivar Regina, cultivada com 15 minutos entre as irrigações, enquanto que Lopes et al. (2003) relatam 450,7 g para a cultivar Lucy Brown, com 10 minutos entre irrigações, em cultivo hidropônico de inverno. Assim, é possível observar que os nossos dados de produção de massa fresca foram consideravelmente inferiores aos relatados na literatura. Sobre isto, Bezerra Neto et al. (2005) indicam que a alface, sendo originada de clima temperado, pode limitar a expressão de seu potencial genético de produção em locais de temperaturas elevadas.

A massa seca acumulada foi menor conforme se aumentou o tempo entre as irrigações (Tabela 2). Os tratamentos apresentaram diferenças significativas entre si, para ambas as cultivares. As maiores médias obtidas foram de 11,2 g.planta-1 (Regina 2000) e 9,7 g.planta-1 (Lucy $^{-1}$ Brown), nas plantas sob 5 min entre irrigações. $\mathrm{O}$ intervalo de 30 min ocasionou as menores médias de acúmulo de massa seca, com valores médios de 5,0 g.planta ${ }^{-1}$ (Regina 2000) e 4,2 g.planta ${ }^{-1}$ (Lucy Brown), conforme mostrado na Tabela 2. Neste tratamento, houve uma redução na massa seca de $55 \%$ (Regina 2000) e $56 \%$ (LucyBrown) em relação ao tratamento $5 \mathrm{~min}$, e de $12 \%$ (Regina 2000) e $20 \%$ (LucyBrown) para o tratamento $15 \mathrm{~min}$.

Tabela 1 - Número de folhas.planta ${ }^{-1}$ e massa fresca total de plantas de alface, cultivares Regina 2000 e Lucy Brown, cultivadas sob três intervalos entre irrigações, em Ji-Paraná/RO, 2006.

\begin{tabular}{ccccc}
\hline \multirow{2}{*}{$\begin{array}{c}\text { Intervalo entre irrigações } \\
\text { (ligado e desligado) }\end{array}$} & \multicolumn{2}{c}{ Folha.planta $^{-1} *$} & \multicolumn{2}{c}{ Massa fresca total $\left(\mathrm{g} \cdot \text { planta }^{-1}\right)^{*}$} \\
\cline { 2 - 5 } & Regina 2000 & Lucy Brown & Regina 2000 & LucyBrown \\
\hline $15 \mathrm{~min} / 05 \mathrm{~min}$ & $30,0 \mathrm{a} \mathrm{a}^{* *}$ & $15,3 \mathrm{a}$ & $200,5 \mathrm{a}$ & $192,3 \mathrm{a}$ \\
\cline { 2 - 5 } $15 \mathrm{~min} / 15 \mathrm{~min}$ & $31,0 \mathrm{a}$ & $12,8 \mathrm{ab}$ & $158,0 \mathrm{~b}$ & $124,4 \mathrm{~b}$ \\
\cline { 2 - 5 } $15 \mathrm{~min} / 30 \mathrm{~min}$ & $20,8 \mathrm{~b}$ & $10,5 \mathrm{~b}$ & $73,3 \mathrm{c}$ & $67,3 \mathrm{c}$ \\
\hline C.V. $(\%)$ & 6,5 & 11,7 & 6,7 & 7,3 \\
\hline
\end{tabular}

*Dados médios de quatro plantas com aproximadamente 45 dias a partir da semeadura.

**Letras minúsculas diferentes significam diferenças estatísticas entre os tratamentos, pelo teste de Tukey, ao nível de 5\% de probabilidade. 
Tabela 2 - Massa seca total de plantas de alface, cultivares Regina 2000 e Lucy Brown, cultivadas sob três intervalos entre irrigações, em Ji-Paraná/RO, 2006.

\begin{tabular}{ccc}
\hline $\begin{array}{c}\text { Intervalo entre irrigações } \\
\text { (ligado e desligado) }\end{array}$ & \multicolumn{2}{c}{ Massa seca total* (g.planta ${ }^{-1}$ ) } \\
\cline { 2 - 3 } $15 \mathrm{~min} / 05 \mathrm{~min}$ & Regina 2000 & Lucy Brown $^{*}$ \\
$15 \mathrm{~min} / 15 \mathrm{~min}$ & $11,2 \mathrm{a}^{* *}$ & $9,7 \mathrm{a}$ \\
$15 \mathrm{~min} / 30 \mathrm{~min}$ & $9,8 \mathrm{~b}$ & $7,8 \mathrm{~b}$ \\
\hline C.V. $(\%)$ & $5,0 \mathrm{c}$ & $4,2 \mathrm{c}$ \\
\hline
\end{tabular}

*Dados médios de quatro plantas com aproximadamente 45 dias a partir da semeadura.

**Letras minúsculas diferentes significam diferenças estatísticas entre os tratamentos, pelo teste de Tukey, ao nível de 5\% de probabilidade.

Avaliando a cultura da alface sob 15 e 30 minutos entre as irrigações, Pillau et al. (2002) obtiveram valores de 15 $\mathrm{g}$ de massa seca por planta, em ambos os intervalos, concluindo que estes tratamentos promoveram respostas semelhantes quanto ao crescimento, durante a primavera e o verão, no município de Santa Maria/RS. Neste mesmo estudo, foram obtidos ciclos médios de produção de 60 dias, superiores aos obtidos em nosso trabalho, que foram aproximadamente de 45 dias. Isso pode ser explicado pela alta média térmica no local de execução do nosso estudo, que foi de $29,3^{\circ} \mathrm{C}$ (Figura 1). Segundo Lopes et al. (2004), um aumento na temperatura do ar, dentro de certos limites, acelera o desenvolvimento da planta, reduzindo o seu ciclo de vida.

Pode-se afirmar que em nosso experimento, o menor acúmulo de massa nas plantas cultivadas com 15 e especialmente 30 minutos entre as irrigações, deveu-se a uma condição de déficit hídrico, relacionado à alta temperatura. Resh (1997) infere que a frequiência dos ciclos de irrigação tem que ser suficiente para impedir o déficit hídrico nas plantas. Neste sentido, a alface é uma hortaliça exigente em água, onde a quantidade e qualidade da mesma influem na produtividade desta cultura (DANTAS, 1997).

Conforme Confalone et al. (1998), o déficit hídrico impõe restrições ao crescimento vegetal, devido a uma não translocação de fotoassimilados na planta, em função de um decréscimo da fotossíntese foliar, além de uma menor expansão das células em virtude de sua baixa turgidez (TAIZ \& ZEIGER, 2002). Este decréscimo na fotossíntese é consequiência, especialmente, de uma diminuição na condutância estomática foliar, o que limita oferta de gás carbônico a este processo e (PEREIRA et al., 2003).

\section{CONCLUSÕES}

Houve decréscimo na produção de ambas as cultivares avaliadas, conforme se aumentou o intervalo entre as irrigações.
Dentre os intervalos entre irrigações testados, 5 minutos mostrou-se o mais favorável à produção das cultivares de alface Regina 2000 e Lucy Brown, em cultivo hidropônico na cidade de Ji-Paraná/RO.

Houve uma redução na produção da alface nos intervalos entre as irrigações de 15 e 30 minutos, para as condições ambientais no local de desenvolvimento do estudo.

\section{REFERÊNCIAS BIBLIOGRÁFICAS}

BEZERRA NETO, F.; ROCHA, R. C. C.; NEGREIROS, M. Z.; ROCHA, R. H.; QUEIROGA, R. C. F. Produtividade de alface em função de condições de sombreamento e temperatura e luminosidade elevadas. Horticultura Brasileira, Brasília, v. 23, n. 2, p. 189-192, 2005.

CARVALHO, J. E.; ZANELLA, F.; MOTA, J. H.; LIMA, A. L. S. Cobertura morcot do solo no cultivo de alface $\mathrm{Cv}$. Regina 2000, em Ji-Paraná/RO. Ciência e Agrotecnologia, Lavras, v. 29, n. 5, p. 935-939, 2005.

CASAROLI, D.; FAGAN, E. B.; SANTOS, O. S.; BONNECARRÈRE, R. A. G.; NOGUEIRA FILHO, H. Desempenho de onze cultivares de alface em duas formas diferentes de canais de cultivo, no sistema hidropônico. Revista da Faculdade de Zootecnia, Veterinária e Agronomia, Uruguaiana, v. 10, p. 114-123, 2003.

CASTELlANE, P. D.; ARAUJO, J. A. C. de. Cultivo sem solo: hidroponia. SOB Informa, Itajaí, v. 13, n. 1, p. 28-29, 1994.

CASTELlane, P. D.; ARAÚJO, J. A. C. de. Cultivo sem solo: hidroponia. 4. ed. Jaboticabal: Funep, 1995. 43 p. 
CONFAlONE, A.; COSTA, L.; PEREIRA, C. R. Crescimento e captura de luz em soja sob estresse hídrico. Revista Brasileira de Agrometeorologia, Santa Maria, v. 6, n. 2, p. 165-169, 1998.

COSTA, L. N. Sistemas produtivos de Rondônia. In: ENCONTRO DE SECRETÁRIOS MUNICIPAIS DE AGRICULTURA DO ESTADO DE RONDÔNIA, 2003, Porto Velho. Anais... Porto Velho: [s.n.], 2003. Disponível em: < w w w.ruralnet.com.br/upload/artigos/ SISTEMAS_PRODUTIVOS_NEWTON.doc $>$. Acesso em: 12 dez. 2006.

DANTAS, R. T. Parâmetros agrometeorológicos e análise de crescimento de alface (Lactuca sativa $\mathrm{L}$.) em ambientes natural e protegido. 1997. 109 f. Dissertação (Mestrado) Faculdade de Ciências Agronômicas, Universidade Estadual de São Paulo, Botucatu, 1997.

FAQUIN, V.; FURLANI, P. R. Cultivo de hortaliças de folhas em hidroponia em ambiente protegido. Informe Agropecuário, Belo Horizonte, v. 20, n. 200/201, p. 99-104, 1999.

FELTRIM, A. L.; CECÍLIO FILHO, A. B.; BRANCO, R. B. F.; BARBOSA, J. C.; SALATIEL, L. T. Produção de alface americana em solo e em hidroponia, no inverno e verão, em Jaboticabal, SP. Revista Brasileira de Engenharia Agrícola e Ambiental, Campina Grande, v. 9, n. 4, p. 505-509, 2005.

FURLANI, P. R. Instruções para o cultivo de hortaliças de folhas pela técnica de hidroponia - NFT. Campinas: Instituto Agronômico, 1997. 30 p. (Boletim técnico, 168).

GÜL, A.; TÜZEL, I. H.; TÜZEL, Y.; ELTEZ, R. Z. Effect of continuous and intermittent solution circulation on tomato plants grown in nft. Acta Horticulturae, Leuven, v. 554, p. 205-212, 2001.

LOPES, M. C.; FREIER, M.; MATTE, J. C.; GÄRTNER, M.; FRANZENER, G.; NOGAROLLI, E. L.; SEVIGNANI, A.
Acúmulo de nutrientes por cultivares de alface em cultivo hidropônico no inverno. Horticultura Brasileira, Brasília, v. 21, n. 2, p. 211-215, 2003.

LOPES, S. J.; DOURADO NETO, D.; MANFRON, P. A.; JASNIEWICZ, L. R. Models to estimate phytomass accumulation of hydroponic lettuce. Scientia Agrícola, Piracicaba, v. 61, n. 4, p. 392-400, 2004.

MORAES, C. A. G. Como cultivar tomates em sistema NFT (Técnica de fluxo laminar de nutrientes). Jundiaí: DISQ, 1997. $141 \mathrm{p}$.

OHSE, S.; DOURADO-NETO, D.; MANFRON, P. A.; SANTOS, O. S. Qualidade de cultivares de alface produzidos em hidroponia. Scientia Agricola, Piracicaba, v. 58, n. 1 , p. 181-185, 2001.

PEREIRA, P. G.; BERGONCI, J. I.; BERGAMASCHI, H.; ROSA, L. M. G.; FRANÇA, S. Efeitos de diferentes níveis de déficit hídrico na fotossíntese e condutância foliar em milho. Revista Brasileira de Agrometeorologia, Santa Maria, v. 11, n. 1, p. 53-62, 2003.

PILLAU, F. G.; MEDEIROS, S. L. P.; MANFRON, P. A.; BIANCHI, C.; CARON, B. O.;

BONNECARRÈRE, R. Influência do intervalo entre irrigações na produção e nas variáveis fisiológicas da alface hidropônica. Revista Brasileira de Agrometeorologia, Santa Maria, v. 10, n. 2, p. 237-244, 2002.

RESH, H. M. Cultivos hidroponicos: nuevas técnicas de producción. 4. ed. Madrid: Mundi, 1997. 509 p.

SILVA, E. L.; MARTINEZ, L. F.; YITAYEW, M. Relação entre coeficientes de cultura e graus-dia de desenvolvimento da alface. Horticultura Brasileira, Brasília, v. 17, n. 2, p. 34-142, 1999.

TAIZ, L.; ZEIGER, E. Plant physiology. 3. ed. Massachussetts: Sinauer Associates, 2002. 690 p. 